\title{
Comparison of the effectiveness of progressive muscle relaxation training, guided imagery and the combination of these two methods on sleep quality and headache coping strategies for women with migraine
}

\author{
Ali Asghar Khosrobeygi \\ Loghman Counseling Center \\ a.khosrobeygi@loghmancpc.ir
}

\begin{abstract}
The purpose of this research is to compare the effectiveness of progressive muscle relaxation training, guided imagery and the combination of these two methods on sleep quality and headache coping strategies for women with migraine in Arak city. The statistical population of this study is all women with migraine headaches in Arak city, and a statistical sample of 90 people was selected by simple random sampling from the referrals to 4 private clinics of neurology and psychiatry. Therefore, 30 subjects were placed in experimental group 1 (relaxation), 30 in experimental group 2 (guided imagery) and 30 in experimental group 3 (combination of these two methods), where the subjects were matched in terms of gender, age and education level. The research method was of extended designs of the experimental designs, and a questionnaire was used in addition to using the library method for collecting data. The scales used in this study were 3 scales of sleep quality, pain (migraine) coping strategies and demographics. Inferential statistics (covariance) were used for data analysis; the results showed that progressive muscle relaxation training, guided imagery, and the combination of these two methods had a positive effect on migraine headache coping strategies and sleep quality in women with migraine. There was also a difference in the effectiveness of the two methods of progressive muscle relaxation, guided imagery and the combination of these two methods on the strategies for coping with migraine headaches and sleep quality of these women, and the combined method was more effective than the other two methods separately.

The studies of this research concluded that the guided imagery technique focuses on cognitive and emotional components and can be used to improve migraine headaches due to the ability of imagination force of people to initiate, exacerbate or sustain attacks of effective headache, as well as the progressive muscle relaxation increases the parasympathetic cycle activity, which consequently leads to nerve stress neutralizing and ineffectiveness, and this adaptive skill prevents raising its symptoms through breaking the chain of undesirable effects of stress, thereby it can improve the quality of life in migraine patients.

Given that migraine is an important health problem, and considering that migraine studies are very limited and little applied research has been conducted in this field, therefore performing a comprehensive study is necessary for developing appropriate strategies.
\end{abstract}

Keywords: migraine headache, progressive muscle relaxation, guided imagery, strategies for coping with migraine headaches and sleep quality.

\section{Introduction}

Migraine is the most common type of headache that is usually unilateral and often has moderate to severe cyclic beating on one side of the head and usually involves headaches, nausea, vomiting, and other symptoms of neurological dysfunction that comes in many forms that exacerbate with usual physical activity (Wei Z. Yeh, 2018).

Page $\mid 1$ 
According to the World Health Organization report (2004), migraine has been ranked the nineteenth among all disorders causing disabilities. Nearly two-quarters of adults aged 18-65 years experienced headache or migraines during a year, and according to the reports of the World Health Organization, ten percent of the world's population has migraine headache, and between $1.7 \%$ and $4 \%$ of the adult population experience headaches or migraines for 15 days or more in a month. Migraine headaches worldwide cause a loss of approximately $1.3 \%$ of the useful life of the affected person (WHO, 2011). According to research, women are twice likely to have migraines as men. Most migraine attacks occur in women during the years of hormonal activity, from adolescence to menopause, and it seems that hormones fluctuations play a greater role than the presence of the hormones themselves in headache attacks (World Health Organization, 2016).

Among the socio-demographic factors, migraine has positive association with depression, bipolar disorder, panic attacks, panic disorder, and simple phobia. There is also evidence that there is a relationship between psychological health and migraine headaches. In addition, the problem of poor sleep quality is seen among migraine patients, such that more than $50 \%$ of migraine patients were confronted with sleep problems and sleep disorders.

Migraine not only causes physical illness, but also causes psychological, social and economic illness in the patient. It lowers the quality of life of the patients to a great extent and also adversely affects the family members of the patient. Losing work, reducing daily activity and reducing interpersonal interactions are some of the problems facing the patient. Although migraine is not considered as a life threat for the patient, but it is considered by the World Health Organization as a chronic disease that can cause disability and should be prevented and treated like other chronic diseases (Supaporn Boonsongsawat, 2018). Due to the disability created for patients, treating migraine and reducing its frequency and severity are very important, and various methods have been proposed for this purpose. One of the ways that may have a significant impact on the severity and duration of migraine headaches is pain coping strategies. Types of coping strategies include problem-focused coping, emotion-focused coping and avoidance coping (Ransom S. et al., 2005). In the problem-focused coping strategy, the individual focuses on the pressing factor and tries to take constructive steps to change the pressing circumstances or to eliminate them. However, in an emotion-focused coping strategy, the individual tries to inhibit the emotional consequences of the pressing event. The primary function of emotion-focused coping is controlling and inhibiting the emotions of the pressing factor for maintaining emotional balance (Lazarus, quoted by Fati, Motabi, Mohammad Khani, Boalhri and Kazemzadeh Atofi, 2006). On the other hand, avoidance coping strategies may also appear in the form of engagement in a new activity or in the form of joining the community and other people. In other words, the individual escapes from the problem and avoids it by keeping distant from it.

This research considers studying the sleep quality and pain coping strategies. For this purpose, two techniques of progressive muscle relaxation and guided imagery have been considered to measure the effectiveness of these two techniques on sleep quality and pain coping strategies for patients with migraine. The technique of progressive muscle relaxation is performed by the individual through creating contrasting states of stretching and loosening the muscles (Andrei-Cătălin Ioniţe, 2017). The main purpose of this method is to reduce the level of general anxiety in the individual, which leads to tension clearance (Casper, Harrison 2005). Learning the principles and arts of this technique is one of the primary needs for coping with pain and tension. The guided imagery method as a mind-body technique is also based on the fact that the mind and the body are interrelated and can affect and strengthen each other in treating the disease and creating health. This method uses the effect of body and mind on each other in relieving pain. In fact, the individual imagines a pleasant image in their mind, then he/she focuses attention on it, which leads to the gradual disappearance of their awareness of pain (Taylor, 2001).

Guided imagery originates in the treatment of the headache from the observation that individuals' imagination can trigger, exacerbate or sustain the headache attacks and increase disability and distress along with the headache. This approach focuses on the cognitive and emotional components of the headache (Marie, 2010; quoted by Saedi and Abolghasemy, 2011).

The same brain region that is activated when experiencing an event is activated in guided imagery; that is,

Page $\mid 2$ 
the individual precisely creates in themself an intellectual stream in which he/she is able to see, hear, feel or smell what he/she wishes to feel at that time and can embody it in their own imagination (Cumps, Haga, Kifeh, Leitenberg and Williams, 1998; quoted by Hajian, Mirzaei Najmabadi, Karamat and Mirzaei, 2008). The three main factors of guided imagery are: attention control, emotional regulation and self-awareness, each of which alone can control the headache caused by migraine in the early stages of a headache (Qiang $\mathrm{Gu}, 2018$ ).

The results of this study show that progressive muscle relaxation reduces overall anxiety levels in the individual and leads to depression clearance, helps control pain and create calmness and improvement of the quality of life in people with chronic migraine (Kroll, 2018). And the technique of guided imagery that gives calmness to the individual by removing the negative emotions of their mind and body, enables them to use a more effective coping strategy to deal with headaches by relying on logic. Training of mental imagery and gradual stress relieving along with biofeedback is effective and efficient in reducing anxiety and headache in migraine patients. In guided imagery, individuals are encouraged to breathe deeply into the abdomen and diaphragm and then release the muscles, imagine views such as forest, seashore, and pilgrimage areas, and focus on the sounds around and the smells. Progressive muscle relaxation and imagery are often used together because imagery can promote the relaxation process and increase its effect.

The aim of this study is to determine the effectiveness of progressive muscle relaxation, guided imagery and the combination of the two methods on migraine headache coping strategies as well as to determine the effectiveness of progressive muscle relaxation, guided imagery and the combination of the two methods on sleep quality in women with migraine and, finally, to compare the effectiveness of progressive muscle relaxation, guided imagery and the combination of these two methods on migraine headache coping strategies as well as to compare the effectiveness of progressive muscle relaxation, guided imagery and the combination of these two methods on sleep quality in women with migraine.

Therefore, these two techniques may affect the sleep quality and pain coping strategies in migraine patients. Considering that migraine studies are very limited and little applied research has been conducted in this field, it seems important and necessary for clinicians to investigate the factors that play a role in the emergence, development and severity of migraine individual attacks and subsequent disability to be able to reduce the frequency of these attacks, control the severity of the symptoms, and limit its impact on psychosocial function in a principle way. Therefore, it seems important and necessary to study the sleep quality and headache coping strategies in migraine patients and determine the effectiveness of the two techniques of progressive muscle relaxation and guided imagery as well as the combination of these two techniques on these components with the aim of reducing and preventing migraine attacks.

In a study by Chiang Gu and Jin Chao Ho (2018), the effect of guided imagery was studied on 315 patients, and the results showed that guided imagery significantly improves the severity of pain in patients. In this analysis of different guided imagery groups, reducing mental-based stress has a positive effect on the severity of pain $(\mathrm{P}<0.000)(\mathrm{Gu} \mathrm{Q} 1,2018)$.

In a research conducted on 200 migraine patients, Boonsongsawat and Taktong (2018) studied the sleep quality and depression in migraine patients and examined the relationship between different factors and sleep quality in patients. The findings showed that most patients had poor sleep $(0.78 \%)$ and low depression level $(0.49 \%)$. The frequency of migraine attack, duration of migraine diagnosis and drug prescription pattern had a significant relationship with sleep quality (P-value $<0.05$ ), so that the sleep quality and depression can be controlled in these patients to a great extent with proper planning and management and using biofeedback and meditation (Boonsongsawat, 2018).

In a study on 25 migraine patients, Mikhail Fominykh et al. (2017) concluded that the training of muscle relaxation technique and the relaxation experience and performing biofeedback can be helpful in improving headache stress in patients (Mikhail Fominykh, 2017).

Morgan et al. (2016) also studied the efficiency of muscle relaxation and the tendency to non-pharmacological treatment on 20 patients aged between 18 and 75 years, where the results of

Page $\mid 3$ 
experiments demonstrated the effectiveness of this technique in the improvement of migraine headaches in the initial stages (Myfanwy Morgan, 2016).

Another study by Donald B. Penzien et al. in 2015 showed significant evidence based on the effectiveness of combined therapies of relaxation, biofeedback, and stress management training, where these techniques are able to compete with migraine drug therapy (Donald B. Penzien, 2015).

In a study by Amy B Wachholtz et al. conducted on 92 subjects and examined headache frequency and severity and the use of pain relieving drugs against the use of guided imagery, it was concluded that migraine headaches were reduced in the groups that performed the guided imagery technique with respect to other groups ( $\mathrm{p}<0.05)$ (Amy B Wachholtz, 2015).

In a study on the effect of biofeedback and relaxation on the treatment of migraine and tension headache on 64 patients aged between 18-55 years who suffered from headaches for more than one year, Meully Hall and Goldstein (2009) showed that the severity and frequency of headache were significantly reduced in $48 \%$ of the patients in the relaxation group and in $35 \%$ of the patients in the biofeedback group after 3 months of experimental work.

Among the studies conducted in this field in Iran, Sepehri et al. (2017) studied the effects of biofeedback with relaxation training on the psychological symptoms in chronic migraine patients in Isfahan, where the results indicated that biofeedback treatment, along with relaxation training, reduces the symptoms in chronic migraine patients. Therefore, this therapeutic approach, along with medication, can be used to reduce the common psychological symptoms in patients and consequently increase the intervals of attacks (Sogol, 2017).

In a cross-sectional study, Bostani et al. (2015) performed sleep disturbance tests and migraine headache symptoms on 1005 students of Kermanshah University of Medical Sciences. The results of this study showed that the prevalence of headache, migraine headache and tension headache in the students of medical sciences was obtained to be $73.8 \%, 16.7 \%$ and $30.9 \%$ respectively. $20.3 \%$ of students had sleep disorder. Disruption in the onset of sleep, daily fatigue, respiratory interruption, and anxiety and sadness are directly related to headache. Moreover, sleep disturbance is directly related to migraine headache $(\mathrm{P}<0.05)$. Regarding the importance of sleep in headache, sleep health training, changes in sleep quality and patterns, use of relaxation and guiding imagery can be a good approach to control headaches in these patients (Bostani, 2015).

In a study conducted in Bushehr, Aghayossefi and Bazyari Meymand (2013) investigated the relationship between general health, resilience and defense mechanisms, and predicted the general health of migraine women who had high resilience and used developed defense mechanisms. They concluded that people with migraine headaches use non-developed and neurotic defense mechanisms, and that there is a significant negative correlation between the deterioration of general health with resilience and also with the developed defense mechanism, and there is a positive significant correlation between this deterioration with non-developed and defense mechanisms and with neurotic defense mechanisms. On the other hand, there is a significant negative correlation between resilience with neurotic defense mechanisms and between resilience with non-developed mechanisms, and there is a significant positive correlation between resilience with developed defense mechanisms. Moreover, in a research with the aim of comparing sleep quality and migraine headaches in individuals with proper and improper sleep in girl and boy students of Urmia, it was concluded that there was a significant difference between the two groups in terms of sleep quality and its sub-scales, namely mental sleep quality, sleep latency, sleep duration, useful sleep, sleep disturbances, consumption of sleep medications, and daily dysfunction, and generally people who do not have good sleep quality are experiencing more migraine headaches and sleep problems during their life (Asadnia, Sepehrianazar, Mosarrezaii Aghdam and Saadatmand, 2012).

Finally, in a research with the aim of investigating and comparing the effectiveness of drug therapy, mental imagery and gradual stress relieving along with biofeedback on the headache of migraine patients in Ahvaz city, it was concluded that the training of mental imagery and gradual stress relieving along with

Page $\mid 4$ 
biofeedback was effective and efficient in reducing anxiety and headache of migraine patients. In the meantime, the approach of gradual stress relieving with biofeedback was more effective than mental imagery in reducing the anxiety and headache of migraine patients, and this superiority remained in the short-term follow-up period (Abolghasemy and Saedi, 2010).

\section{The Findings}

The descriptive statistics related to variables were extracted first and then the results of the pretest and posttest of the experiment groups were examined, as shown in Tables 1 and 2.

Table 1 presents the mean, standard deviation and variance of demographic variables such as age, occupation, marital status and education.

Table 1. Descriptive statistics of subjects' characteristics

\begin{tabular}{|l|l|l|l|l|}
\hline Variables & Number & Mean & $\begin{array}{l}\text { Standard } \\
\text { deviation }\end{array}$ & Variance \\
\hline Education & 90 & 1.82 & 1.02 & 1.04 \\
\hline Age & 90 & 2.71 & 0.89 & 0.79 \\
\hline Occupation & 90 & 1.38 & 0.68 & 0.46 \\
\hline $\begin{array}{l}\text { Marital } \\
\text { status }\end{array}$ & 90 & 1.26 & 0.44 & 0.19 \\
\hline
\end{tabular}

Table 2 presents descriptive statistics of variables such as pain severity, sleep quality and coping strategies of the three groups in the two stages of pretest and posttest.

Table 2. Descriptive statistics of independent and dependent variables in the two stages of pretest and posttest of the three experimental groups

Descriptive statistics of independent variables in the two stages of pretest and posttest of the three experimental groups

\begin{tabular}{|c|c|c|c|c|}
\hline Title & Mean & Variance & $\begin{array}{c}\text { Standard } \\
\text { deviation }\end{array}$ & Mean deviation error \\
\hline $\begin{array}{c}\text { Pretest headache severity in the } \\
\text { relaxation group }\end{array}$ & 10.9095 & 10.972 & 3.31237 & 0.60475 \\
\hline $\begin{array}{c}\text { Posttest headache severity in the } \\
\text { relaxation group }\end{array}$ & 7.2857 & 1.754 & 1.32427 & 0.24187 \\
\hline $\begin{array}{c}\text { Pretest headache severity in the } \\
\text { guided imagery group }\end{array}$ & 12.4810 & 2.980 & 3.60281 & 0.65778 \\
\hline $\begin{array}{c}\text { Posttest headache severity in the } \\
\text { guided imagery group }\end{array}$ & 9.3333 & 6.614 & 2.57179 & 0.46954 \\
\hline $\begin{array}{c}\text { Pretest headache severity in the } \\
\text { combined group }\end{array}$ & 7.8095 & 5.648 & 2.23847 & 0.42694 \\
\hline
\end{tabular}

Page $\mid 5$ 


\begin{tabular}{|c|c|c|c|c|}
\hline $\begin{array}{l}\text { Posttest headache severity in the } \\
\text { combined group }\end{array}$ & 5.7857 & 11.503 & 3.39158 & 0.61921 \\
\hline \multicolumn{5}{|c|}{ Descriptive statistics of research dependent variables in the two stages of pretest and posttes } \\
\hline $\begin{array}{l}\text { Pretest pain coping strategies for } \\
\text { the relaxation group }\end{array}$ & 3.1817 & 0.140 & 0.37453 & 0.06838 \\
\hline $\begin{array}{l}\text { Posttest pain coping strategies for } \\
\text { the relaxation group }\end{array}$ & 3.4080 & 0.165 & 0.40662 & 0.07424 \\
\hline $\begin{array}{l}\text { Pretest sleep quality for the } \\
\text { relaxation group }\end{array}$ & 12.7000 & 2.424 & 1.55696 & 0.28426 \\
\hline $\begin{array}{l}\text { Posttest sleep quality for the } \\
\text { relaxation group }\end{array}$ & 4.3667 & 2.447 & 1.56433 & 0.28561 \\
\hline $\begin{array}{l}\text { Pretest pain coping strategies for } \\
\text { the guided imagery group }\end{array}$ & 3.2043 & 0.157 & 0.39566 & 0.07224 \\
\hline $\begin{array}{l}\text { Posttest pain coping strategies for } \\
\text { the guided imagery group }\end{array}$ & 3.4613 & 0.097 & 0.31139 & 0.05685 \\
\hline $\begin{array}{l}\text { Pretest sleep quality for the } \\
\text { guided imagery group }\end{array}$ & 12.2667 & 7.444 & 2.72831 & 0.07224 \\
\hline $\begin{array}{l}\text { Posttest sleep quality for the } \\
\text { guided imagery group }\end{array}$ & 4.7667 & 3.771 & 1.94197 & 0.35455 \\
\hline $\begin{array}{l}\text { Pretest pain coping strategies for } \\
\text { the combined group }\end{array}$ & 3.1163 & 0.122 & 0.34891 & 0.06370 \\
\hline $\begin{array}{l}\text { Posttest pain coping strategies for } \\
\text { the combined group }\end{array}$ & 3.7360 & 0.022 & 0.14915 & 0.02723 \\
\hline $\begin{array}{l}\text { Pretest sleep quality for the } \\
\text { combined group }\end{array}$ & 14.8333 & 7.109 & 2.66631 & 0.48680 \\
\hline $\begin{array}{l}\text { Posttest sleep quality for the } \\
\text { combined group }\end{array}$ & 0.7667 & 0.323 & 0.56832 & 0.10376 \\
\hline
\end{tabular}

As can be seen in the above table, the headache score, which is considered from zero to ten in all three groups, is reduced after performing relaxation, guided imagery and the combination of these two methods. It is worth noting that the first four weeks of completing the headache severity checklist were considered as pretest and the second four weeks were considered as posttest. Moreover, according to the above table, a change in the mean of coping strategies and an increase in the average of sleep quality are seen in the posttest in the three groups.

Furthermore, covariance analysis was used in this research to test the hypotheses. The assumptions of this test are Kolmogorov-Smirnov test and Levene's test, where the normality of data or the adherence of data to the uniform and Poisson distribution can be determined by Kolmogorov-Smirnov method, and the homogeneity of variance in the experimental groups can be investigated using Levene's test.

Table 3. Kolmogorov-Smirnov of the dependent variable of headache coping strategies in the relaxation, guided Page $\mid 6$ 
imagery and the combined groups, and sleep quality in the relaxation group, sleep quality in the guided imagery group, sleep quality in the combined group

\begin{tabular}{|c|c|c|c|c|c|}
\hline Title & Number & Mean & $\begin{array}{l}\text { Standard } \\
\text { deviation }\end{array}$ & Kolmogorov-Smirnov & $\begin{array}{c}\text { Significance } \\
\text { level }\end{array}$ \\
\hline $\begin{array}{l}\text { Pretest of headache } \\
\text { coping strategies in } \\
\text { the relaxation group }\end{array}$ & 30 & 3.1817 & 0.37453 & 0.605 & 0.858 \\
\hline $\begin{array}{l}\text { Posttest of headache } \\
\text { coping strategies in } \\
\text { the relaxation group }\end{array}$ & 30 & 3.4080 & 0.40662 & 1.547 & 0.617 \\
\hline $\begin{array}{l}\text { Pretest of headache } \\
\text { coping strategies in } \\
\text { the guided imagery } \\
\text { group }\end{array}$ & 30 & 3.2043 & 0.39566 & 0.676 & 0.752 \\
\hline $\begin{array}{l}\text { Posttest of headache } \\
\text { coping strategies in } \\
\text { the guided imagery } \\
\text { group }\end{array}$ & 30 & 3.4613 & 0.31139 & 1.371 & 0.647 \\
\hline $\begin{array}{l}\text { Pretest of headache } \\
\text { coping strategies in } \\
\text { the combined group }\end{array}$ & 30 & 3.1163 & 0.34891 & 0.775 & 0.586 \\
\hline $\begin{array}{l}\text { Posttest of headache } \\
\text { coping strategies in } \\
\text { the combined group }\end{array}$ & 30 & 3.7360 & 0.14915 & 1.263 & 0.082 \\
\hline $\begin{array}{l}\text { Pretest of sleep } \\
\text { quality in the } \\
\text { relaxation group }\end{array}$ & 30 & 12.7000 & 1.55696 & 0.784 & 0.571 \\
\hline $\begin{array}{l}\text { Posttest of sleep } \\
\text { quality in the } \\
\text { relaxation group }\end{array}$ & 30 & 4.3667 & 1.56433 & 1.603 & 0.062 \\
\hline $\begin{array}{l}\text { Pretest of sleep } \\
\text { quality in the guided } \\
\text { imagery group }\end{array}$ & 30 & 12.2667 & 2.72831 & 0.827 & 0.500 \\
\hline $\begin{array}{l}\text { Posttest of sleep } \\
\text { quality in the guided } \\
\text { imagery group }\end{array}$ & 30 & 4.7667 & 1.94197 & 1.388 & 0.072 \\
\hline $\begin{array}{l}\text { Pretest of sleep } \\
\text { quality in the }\end{array}$ & 30 & 14.8333 & 2.66631 & 0.685 & 0.736 \\
\hline
\end{tabular}

Page $\mid 7$ 


\begin{tabular}{|l|l|l|l|l|l}
\hline combined group & & & & & \\
\hline $\begin{array}{l}\text { Posttest of sleep } \\
\text { quality in the } \\
\text { combined group }\end{array}$ & 30 & 0.7667 & 0.56832 & 1.968 & 0.100 \\
\hline
\end{tabular}

According to the output of the abovementioned illustrations, since the significance level associated with the variable of headache coping strategies in the pretest and posttest of all three groups is greater than 0.05 , then the assumption of the normality of the data will be accepted, and also since the significance level associated with the variable of sleep quality in the pretest and posttest of all three groups is greater than 0.05 , then the assumption of the normality of data will be accepted.

The table of the results of the tested hypotheses is the following:

Table 4. Results of the tested hypotheses

\begin{tabular}{|c|c|c|c|c|c|c|c|}
\hline $\begin{array}{l}\text { Hypot } \\
\text { hesis }\end{array}$ & Variable & $\begin{array}{c}\text { Sum of } \\
\text { squares }\end{array}$ & DOF & $\begin{array}{c}\text { Mean } \\
\text { square }\end{array}$ & $\mathbf{F}$ & $\begin{array}{c}\text { Significance } \\
\text { level }\end{array}$ & $\begin{array}{c}\text { Effect } \\
\text { factor ETA }\end{array}$ \\
\hline First & Relaxation & 4.820 & 34 & 0.142 & 0.842 & 0.033 & 0.544 \\
\hline Second & $\begin{array}{l}\text { Guided } \\
\text { imagery }\end{array}$ & 5.258 & 40 & 0.131 & 1.130 & 0.002 & 0.715 \\
\hline Third & $\begin{array}{c}\text { Combined } \\
\text { method }\end{array}$ & 3.362 & 24 & 0.140 & 5.851 & 0.000 & 0.805 \\
\hline Fourth & Relaxation & 104.867 & 34 & 3.084 & 2.034 & 0.037 & 0.742 \\
\hline Fifth & $\begin{array}{l}\text { Guided } \\
\text { imagery }\end{array}$ & 9.234 & 1 & 9.234 & 5.877 & 0.026 & 0.246 \\
\hline Sixth & $\begin{array}{c}\text { Combined } \\
\text { method }\end{array}$ & 161.390 & 24 & 6.725 & 4.223 & 0.000 & 0.749 \\
\hline $\begin{array}{c}\text { Sevent } \\
\mathrm{h}\end{array}$ & $\begin{array}{c}\text { Pain } \\
\text { coping } \\
\text { strategy }\end{array}$ & 0.456 & 1 & 0.456 & 2.484 & 0.020 & 0.805 \\
\hline Eighth & $\begin{array}{c}\text { Sleep } \\
\text { quality }\end{array}$ & 1520.067 & 1 & 1520.067 & 204.241 & 0.000 & 0.749 \\
\hline
\end{tabular}

The first hypothesis test is that progressive muscle relaxation training is effective on migraine headache coping strategies. After performing covariance analysis and according to the above table, since the significance level is equal to 0.033 and is less than 0.05 , so the first hypothesis is accepted. The effect factor of relaxation training on pain coping strategies is as much as ETA factor of (0.544). This means that 0.544 of the changes in the mean of posttest scores with respect to the pretest is due to the progressive muscle relaxation training. 
The second hypothesis test is that guided imagery training is effective on migraine headache coping strategies. After performing covariance analysis and according to the above table, since the significance level is equal to 0.002 and less than 0.05 , so the second hypothesis is accepted. The effect factor of guided imagery training on pain coping strategies is as much as ETA factor of 0.715 . This means that 0.715 of the changes in the mean of posttest scores with respect to the pretest is due to the guided imagery training.

The third hypothesis test is that the combination of the two methods of progressive muscle relaxation training and guided imagery is effective on migraine headache coping strategies. After performing the covariance analysis, and according to the above table, since the significance level is equal to 0.000 and less than 0.005 , so the third hypothesis is accepted. The effect factor of the combined method on pain coping strategies is as much as ETA factor of 0.805 . This means that 0.805 of the changes in the mean of posttest scores with respect to the pretest is due to the combined training of both progressive muscle relaxation and guided imagery.

The fourth hypothesis test is that progressive muscle relaxation is effective on the sleep quality in women with migraine. After performing the covariance analysis and according to the above table, since the significance level is equal to 0.073 and less than 0.05 , so this hypothesis is accepted. The effect factor of relaxation training on the sleep quality of women with migraine is as much as ETA factor of 0.742 . This means that 0.742 of the changes in the mean of posttest scores with respect to the pretest is due to progressive muscle relaxation.

The fifth hypothesis test is that guided imagery training is effective on the sleep quality in women with migraine. After performing the covariance analysis and according to the above table, since the significance level is equal to 0.026 and less than 0.05 ; so this hypothesis is accepted. The effect factor of guided imagery on the sleep quality in women with migraine is as much as ETA factor of 0.246 . This means that 0.246 of the changes in the mean of posttest scores with respect to the pretest is due to guided imagery training.

The sixth hypothesis test is that the combination of the two methods of progressive muscle relaxation and guided imagery is effective on sleep quality in women with migraine. After performing the covariance analysis and according to the above table, since the significance level is equal to 0.000 and less than 0.05 , so this hypothesis is accepted. The effect factor of the combined training on sleep quality in women with migraine is as much as ETA factor of 0.749 . This means that 0.749 of the changes in the mean posttest scores with respect to the pretest is due to the combined training.

The seventh hypothesis test is that there is difference between the efficiency of the methods of relaxation, guided imagery, and the combination of these two methods on migraine headache coping strategies. According to the above table, it is observed that the significance level is less than 0.05 , so there is difference between the efficiency of the methods of relaxation, guided imagery and the combination of these two methods on migraine headache coping strategies. According to the obtained ETA factor (0.805) by the covariance, it was determined that the effect of the combined method is more than the effect of the two methods of relaxation and guided imagery on headache coping strategies of women with migraine.

The eighth hypothesis test is that there is difference between the efficiency of the methods of relaxation, guided imagery and the combination of these two methods on sleep quality in women with migraines. According to the above table, it is seen that the significance level is less than 0.05 , so there is difference between the efficiency of the methods of relaxation, guided imagery, and the combination of these two methods on sleep quality in women with migraines. According to the obtained ETA coefficient (0.749) by covariance, it was determined that the efficiency of the combined method is more than the efficiency of the two methods of relaxation and guided imagery on sleep quality in women with migraine.

\section{Discussion and Conclusion}

This study was held with the aim to determine the efficiency of progressive muscle relaxation, guided imagery, and the combination of these two methods on migraine headache coping strategies as well as to determine the effectiveness of progressive muscle relaxation, guided imagery, and the combination of these

Page $\mid 9$ 
two methods on the sleep quality of women with migraine, and finally to compare the effectiveness of progressive muscle relaxation, guided imagery and the combination of these two methods on migraine headache coping strategies as well as to compare the effectiveness of progressive muscle relaxation, guided imagery and the combination of these two methods on the sleep quality of women with migraine.

The findings showed that progressive muscle relaxation is effective on migraine headache coping strategies. Considering the comparison of the results of this research with the results of other similar studies, Mikhail Fominykh et al. (2017) in a study on 25 patients with migraine, concluded that training the technique of muscle relaxation and calmness and the implementation of biofeedback can be beneficial in improving headache stress in patients (Mikhail Fominykh, 2017), the result of this experiment is consistent with the findings of the present research. Furthermore, in a study on the effect of relaxation on the treatment of migraine and headache-caused tension, Meully, Hall and Goldstein (2009) showed that the severity and frequency of headache of $48 \%$ of patients in the relaxation group have significantly reduced after three months of experimental work, but in explaining this finding it can be said that in progressive muscle relaxation, people gradually learn how to reduce tension of the muscles (Inner Health Studio, 2015).

Research findings also showed that guided imagery is effective on migraine headache coping strategies. Considering the comparison of the results of the present research with other similar studies, such as studies related to the effects of mental imaging on the treatment of tension headaches held by Chiang Gu and Jin Chao Ho (2018), which studied the effect of guided imagery on 315 patients and whose results showed that guided imagery significantly improved the severity of pain in patients, in this analysis of different guided imagery groups, reducing mental stress had a positive effect on the severity of pain. Amy B Wachholtz et al. conducted a study on 92 subjects, and investigated the frequency of headache, headache severity, and the use of pain relieving drugs against the use of guided imagery, and concluded that migraine headaches was reduced in the groups that had the guided imagery technique with respect to other groups $(p<0.05)$ (Amy B Wachholtz, 2015). Therefore, the guided imagery technique, with the relaxation that provides to the individual by bypassing the negative emotions of their mind and body, enables them to apply a more effective coping strategy to cope with headaches by relying on logic. Therefore, the above findings can be explained.

According to the research findings, the combination of the two methods of progressive muscle relaxation and guided imagery is effective on migraine headache coping strategies. Considering the comparison of the results of this research with other similar studies, Abolghasemy and Saedi (2010) in the research concluded that the training of mental imagery and gradual stress relief along with biofeedback was effective and efficient in reducing anxiety and headache in patients with migraine, and in the meantime, the gradual stress relief approach along with biofeedback was more effective than mental imagery in reducing the anxiety and headache in patients with migraine, but in explaining this finding it can be said that according to the above findings that the relaxation and guided imagery had positive effect on headache coping strategies, the combination of these two methods creates, of course, a more complete technique that has more effect on the strategies. Therefore, this finding can also be explained.

The results also showed that progressive muscle relaxation is effective on sleep quality in women with migraines. Considering the comparison of the results of this research with the results of other similar studies, Boonsongsawat and Taktong (2018), who conducted a study on 200 patients with migraine to investigate the sleep quality and the degree of depression in migraine patients and the relationship between different factors and sleep quality in patients and concluded that most patients had poor sleep $(0.78 \%)$ and low depression level $(0.49 \%)$, is consistent with our findings. The frequency of migraine attack, duration of migraine diagnosis and drug prescription pattern had a significant relationship with sleep quality (P-value $<0.05)$, so that the sleep quality and depression can be controlled in these patients to a great extent with proper planning and management and using biofeedback and meditation (Boonsongsawat, 2018). In a cross-sectional study, Bostani et al. (2015) performed sleep disturbance tests and migraine and tension headache symptoms on 1005 students of Kermanshah University of Medical Sciences, where the results showed that the general prevalence of headache, migraine headache and tension headache in the students of

Page $\mid 10$ 
medical sciences was obtained to be $73.8 \%, 16.7 \%$ and $30.9 \%$ respectively. $20.3 \%$ of students had sleep disorder. Disruption in the onset of sleep, daily fatigue, respiratory interruption, and anxiety and sadness are directly related to headache. Moreover, sleep disorder is directly related to migraine headache $(\mathrm{P}<0.05)$. Regarding the importance of sleep in headache, it was concluded that sleep health training and changes in sleep quality and sleep patterns can be a good approach to control headaches in these patients (Bostani, 2015).

In explaining this finding it can be said that sleep disorders are common in people with headache and are more common in chronic forms of headaches and patients with psychiatric disorders, as well as chronic pain may be the cause of poor sleep quality (Thomas, Sarado, Vichio, Serpino and Astasi, 2008). As a result, this technique improves sleep quality by reducing headaches. Therefore, this finding can also be explained.

The research results indicate that guided imagery is effective of sleep quality in women with migraine. Considering the comparison of the results of this research with other results of similar studies, it can be said that guided imagery originates in the treatment of the headache from the observation that individuals' imagination can trigger, exacerbate or sustain the headache attacks and increase disability and distress along with the headache. This approach focuses on the cognitive and emotional components of the headache (Marie, 2010; quoted by Saedi and Abolghasemy, 2011); therefore, by reducing headache and providing physical and mental relaxation to patients, their sleep quality are also affected and improved. Thus, this finding can also be explained.

The findings of this research indicated that the combination of the two methods of progressive muscle relaxation and guided imagery is effective on the sleep quality of women with migraine. Considering the comparison of the results of this research with other results of similar studies, it can be said that considering the above findings that relaxation and guided imagery had a positive effect on sleep quality in women with migraine, then the combination of these two methods certainly provides a more complete technique that has a better effect on sleep quality. Therefore, this finding can also be explained.

In explaining the findings of the research that there is a difference between the effectiveness of the two methods of progressive muscle relaxation, guided imagery and the combination of these two methods on the strategies for coping with migraine headache, this hypothesis was confirmed. Considering the comparison of the results of this research with other results of similar studies, it can be said that progressive muscle relaxation is very effective and increases the activity of the parasympathetic cycle, which consequently leads to nerve stress neutralizing and ineffectiveness (Behroozi, 2001). The same brain region that is activated when experiencing an event is activated in guided imagery; that is, the individual precisely creates in themself an intellectual stream in which he/she is able to see, hear, feel or smell what he/she wishes to feel at that time and can embody it in their own imagination (Cumps, Haga, Kifeh, Leitenberg and Williams, 1998; quoted by Hajian, Mirzaei Najmabadi, Karamat and Mirzaei, 2008).

The three main factors of guided imagery are: attention control, emotional regulation and self-awareness, each of which alone can control the headache caused by migraine in the early stages of a headache (Qiang $\mathrm{Gu}, 2018$ ). These two techniques are complementary to each other, and their combination creates a way that both mind and body reach the maximum relaxation, therefore, its effectiveness will certainly be higher than that of each technique separately. As a result, the individual can use better strategies to cope with headaches.

Finally, there is a difference between the effectiveness of the two methods of relaxation, guided imagery, and the combination of these two methods on sleep quality in women with migraine, and this hypothesis was confirmed. Considering the comparison of the results of this research with other results of similar studies, it can be said that considering the subjects mentioned in the previous hypothesis, the two techniques are complementary to each other, and the relaxation that the individual gains from the combination of these two techniques is more than that of each technique separately. As a result, the physical and mental relaxation obtained by combining these two techniques will definitely lead to a greater improvement in the sleep quality than each technique separately. Therefore, this finding can be explained.

Page $\mid 11$ 
The following results were also obtained as side data:

Of the 90 subjects, 50 people $(55.6 \%)$ had diplomas and lower, $12(13.3 \%)$ had associate degree, $22(24.4 \%)$ had bachelor degree, and $6(6.7 \%)$ had masters degree. Moreover, 8 of them (i.e. $8.9 \%)$ were in the age range of $19-25$ years, 28 people (31.1\%) were in the age range of $26-32,36$ people $(40 \%)$ were in the age range of 33-39, and $18(20 \%)$ were in the age range of 40-47 years. 64 women $(71.1 \%)$ were housewives, $20(22.2 \%)$ were employees, $4(4.4 \%)$ were teachers and $2(2.2 \%)$ were students. 67 people $(74.4 \%)$ were married and $23(25.6 \%)$ were single. Headache was reduced in the second four weeks after the implementation of the techniques.

\section{References}

Sogol; S. F. (2017). The effectiveness of electromyography biofeedback with relaxation training on the reduction of the duration of headaches in migraine patients. Advances in Cognitive Science.

Bostani, Kh. (2015). The comparison of sleep disturbances between the subjects with headache and healthy subjects. Journal of Kermanshah University of Medical Sciences, 269.

Asadnia Saed; Sepehrianazar Ferozeh; Mosarrezaii Aghdam Arash and Saadatmand Saed. (2013). Comparison of sleep quality and migraine headaches in people with proper and improper and poor sleep. Journal of Urmia University of Medical Sciences, 23 (7): 799-806.

Parvaz, Younes; Parvaz, Sohela and Jahanbaznejad, Khubaneh. (2011). A comparative study of personality characteristics in migraine patients and healthy subjects through MMPI personality questionnaire. Journal of Clinical Psychology Studies, 3(1): 61-79.

Saedi, Sara and Abolghasemy, Shahnam. (2011). The effect of guided imagery and relaxation therapy on allaying the headache and headache-caused disability in women with migraine. Journal of Women and Culture, 3(10): 39-52.

Toubaei Shahin and Farrashbandi Hasan. (2010). Assessment of personality characteristics in migraine patients. Journal of Urmia University of Medical Sciences, 21(2):280-285.

Rezaei Sajjad; Afsharnejad Taher; Kafi Mousa; Soltani Reza; Fallahkohan Safieh. Relationship between Depression and Coping Strategies in Chronic Back Pain Patients. Daneshvar Medicine. 2009; 16(81): 63-74.

Azizi Masoomeh. (2010). A study on the role of coping Strategies in decreasing depression caused by Mammogram Pain. Journal of Research in Psychological Health, 3(4): 27-36.

Farhadi Nasab A. and Azimi H. (2008). Study of patterns and subjective quality of sleep and their correlation with personality traits among medical students of Hamadan University of Medical Sciences. Avicenna Journal of Clinical Medicine, 15(1): 11-15.

Safavi, Mahbobeh; Nazari, Fatemeh and Mahmoody-Majdabady Mahmood (2008). The relationship of migraine headache and lifestyle among women. Iran Journal of Nursing, 21(55): 89-100.

Page $\mid 12$ 